\title{
Thinking Outside the Visit: Primary Care Patient Perspectives on Helpful Advance Care Planning Methods
}

\author{
Leslie W. Suen, $\mathrm{MD}^{7}{ }^{\mathbb{D}}$, Sarah Leyde, $\mathrm{MD}^{7}$, Kathleen Min, $\mathrm{MD}^{7}$, Aiesha Volow, MPH${ }^{2}$, \\ Michael Rabow, $M D^{3}$, and Rebecca L. Sudore, $M D^{2,4,5}$
}

'Division of General Internal Medicine, Department of Medicine, University of California, San Francisco, San Francisco, CA, USA; ${ }^{2}$ Division of Geriatrics, Department of Medicine, University of California, San Francisco, San Francisco, CA, USA; ${ }^{3}$ Division of Palliative Medicine, Department of Medicine, University of California, San Francisco, San Francisco, CA, USA; ${ }^{4}$ Innovation and Implementation Center in Aging and Palliative Care Research (I-CAP), University of California, San Francisco, San Francisco, CA, USA; ${ }^{5}$ San Francisco Veterans Affairs Medical Center, San Francisco, CA, USA.

J Gen Intern Med 35(6): 1903-5

DOI: $10.1007 / \mathrm{s} 11606-019-05367-y$

() Society of General Internal Medicine 2019

\section{INTRODUCTION}

Advance care planning (ACP) is the process of planning for future medical care with the goal of helping patients receive care aligned with their preferences. Patients who engage in $\mathrm{ACP}$ with their primary care provider (PCP) report increased satisfaction and quality of life, and ACP is a key quality metric in primary care. ${ }^{1,2}$ Unfortunately, rates of ACP engagement remain low, with PCPs identifying lack of time during visits as a major barrier. ${ }^{3,4}$ Although tools exist to engage patients in ACP outside of the traditional primary care visit, patient perspectives of the acceptability of these methods are unknown. This qualitative study explored patients' perceptions and acceptability of various ACP outreach methods available to directly engage patients outside of an office visit.

\section{METHODS}

We conducted a qualitative study to assess strategies for ACP engagement outside the primary care visit using the perspectives gained from two focus groups of older primary care patients. Participants were recruited from an urban, academic adult primary care clinic and were eligible if 65 years of age or older and fluent in English. Using a semi-structured focus group guide, participants were asked for their opinions after being shown different examples of ACP methods (Table 1). After discussion, participants completed a survey rating the acceptability of each method. Focus groups were audiorecorded, professionally transcribed, and independently coded

\footnotetext{
$\overline{\text { Prior Presentations This work was presented at the } 2019 \text { Annual }}$ Society of General Internal Medicine (SGIM) Meeting on May 10, 2019.

Leslie W. Suen, Sarah Leyde, and Kathleen Min are co first-authors.

Received August 10, 2019

Revised August 10, 2019

Accepted September 12, 2019

Published online October 25, 2019
}

by three researchers to analyze for themes using an inductive approach. ${ }^{5}$ This study was approved by the Institutional Review Board at the UCSF.

\section{RESULTS}

Of the 14 participants in the two focus groups, 57\% were women and the mean age was 72 years (standard deviation 4.4 years). Participants were racially/ethnically diverse $(8 \%$ Latinx, 13\% Asian/Pacific Islander, 20\% Black/African American, $47 \%$ White/Caucasian, $13 \%$ other) and highly educated (100\% completed a college degree). Twenty-one percent had been hospitalized in the past year and $57 \%$ had previously engaged in ACP. We identified four themes (Table 1):

1. Patient/provider relationship: Participants viewed ACP discussions as deeply personal and nuanced, and underscored the importance of the provider/patient relationship. Encouragement from PCPs was cited as a major motivator to engage in ACP. Outreach methods (e.g., mailings) were felt to be more powerful if they were seen as coming from the PCP or their clinic or health center, especially when paired with an upcoming visit.

2. Multimodal approach: A variety of ACP outreach methods are necessary to accommodate the spectrum of patient preferences, health literacy, computer literacy, and readiness to engage. Group visits, educational mailings, and interactive websites were rated highly (Table 2). Furthermore, technology could be used to augment ACP (e.g., websites, electronic reminders, webinars), but should not replace in-person discussions with PCPs.

3. Nudges: Participants found repeated "nudges" (reminders) over time to be helpful. Reminders were welcomed by patients and helped them reach a threshold to then engage with ACP. Reminders also underscored $\mathrm{ACP}$ as an iterative process as opposed to a singular event. 
Table 1 Themes of Patient Perspectives Regarding Advance Care Planning (ACP) Methods

\begin{tabular}{|c|c|}
\hline Themes & Exemplary quotes \\
\hline $\begin{array}{l}\text { Patient/provider } \\
\text { relationship }\end{array}$ & $\begin{array}{l}\text { "If I had the sense that this was very important to my primary care doctor and she wanted me to be initiated in this, } \\
\text { I would sit down, and I would do it seriously." }\end{array}$ \\
\hline Multimodal approach & $\begin{array}{l}\text { "It sounds like there are many different ways [to engage in ACP] and there's more than one answer." } \\
\text { "Different approaches can be good for different types of people." }\end{array}$ \\
\hline Nudges & $\begin{array}{l}\text { "I think [the doctor] pursued it time and again, and he would give us forms to fill out. } \\
\text { You're at a point in your life that you do not want to think about it and eventually there comes a time when you need to } \\
\text { think about it, so it was really him pushing these forms at us that we finally took action..." } \\
\text { "Sometimes it's just a nudging reminder." }\end{array}$ \\
\hline Dialogue & $\begin{array}{l}\text { "Maybe tying this [outreach letter] to a visit might be helpful because people can ask questions." } \\
\text { "Rather than push it as questions, [advance care planning] should always be a dialogue." } \\
\text { "People at our age, I think the more human contact the better. } \\
\text { Otherwise, it's very impersonal and it's alienating, dehumanizing." }\end{array}$ \\
\hline
\end{tabular}

4. Dialogue: Participants underscored the importance of "human connection" when discussing ACP, citing need for "dialogue" and the ability to ask questions. While participants found different outreach methods acceptable, they saw most as "too monologue" and were less interested in educational materials in a vacuum, as this felt too impersonal for such an intimate topic. Thus, engagement methods should be paired with opportunities to ask questions and allow for discussion.

\section{DISCUSSION}

Our findings underscore key aspects of a comprehensive approach to ACP, including the importance of the $\mathrm{PCP} /$ patient relationship, offering a menu of multimodal approaches to engage patients, and pairing approaches with further opportunities for dialogue. Our study supports prior research that found the most successful ACP interventions involve some form of discourse and direct, iterative interactions, while passive education modalities without direct counseling are less effective. $^{3,4}$ In our study, group visits were voted as the most favorable method for ACP outreach, with personalized mailings and web-based programs also highly rated. The small sample size of educated participants who were willing to attend a focus group may decrease the generalizability of our findings. However, the sample was diverse and findings about group visits are consistent with prior studies. Our findings thus inform how future strategies can be tailored to the needs of patients to allow for increased engagement in ACP.

Contributors: None.

Corresponding Author: Leslie W. Suen, MD; Division of General Internal Medicine, Department of Medicine University of California, San Francisco, 1545 Divisadero Street, Box 0320, San Francisco, CA 94115, USA (e-mail: leslie.suen@ucsf.edu).

Funding Information Drs. Leyde, Min, and Suen were funded by the 2018 UCSF Pathways to Discovery Grant for Resident Research. Dr. Sudore is funded in part by the National Institute in Aging (K24AG054415).

\section{Compliance with Ethical Standards:}

This study was approved by the Institutional Review Board at the UCSF.

Conflict of Interest: The authors declare that they do not have a conflict of interest.

\section{REFERENCES}

1. Tierney WM, Dexter PR, Gramelspacher GP, Perkins AJ, Zhou X-H, Wolinsky FD. The effect of discussions about advance directives on patients' satisfaction with primary care. J Gen Intern Med. 2001;16(1):3240.

2. Detering KM, Hancock AD, Reade MC, Silvester W. The impact of advance care planning on end of life care in elderly patients: Randomised controlled trial. BMJ. 2010;340(7751):847. https://doi.org/10.1136/bmj. c1345

3. Ramsaroop SD, Reid MC, Adelman RD. Completing an advance directive in the primary care setting: What do we need for success? J Am Geriatr Soc. 2007;55(2):277-283. https://doi.org/10.1111/j.1532-5415.2007.01065.x

Table 2 Patient Ratings of Acceptability of Various Advance Care Planning (ACP) Methods

\begin{tabular}{ll}
\hline \hline Method & Description \\
\hline Group visits & Group medical visits focused on ACP \\
Mailings & Letter encouraging patients to engage in ACP sent to home address \\
Websites & Interactive ACP websites for patients to engage with at home \\
Phone calls & Administrative clinic staff calling patients to encourage them to engage in ACP \\
Movies in waiting room & Movies playing in the clinic waiting room encouraging ACP \\
\hline
\end{tabular}

*Participants were asked to rate acceptability of each method using a 5-point Likert scale $(1=$ strongly disagree, $2=$ disagree, $3=$ neutral, $4=$ agree, $5=$
+ strongly agree). Average rating with standard deviation and range of responses is displayed 
4. Heiman H, Bates DW, Fairchild D, Shaykevich S, Lehmann LS Improving completion of advance directives in the primary care setting: A randomized controlled trial. Am J Med. 2004;117(5):318-324. https://doi. org/10.1016/j.amjmed.2004.03.027

5. Maxwell J. Qualitative Research Design: An Interactive Approach. 3rd ed. Thousand Oaks, CA: Sage Publications; 2013.

6. Sudore RL, Boscardin J, Feuz MA, McMahan RD, Katen MT, Barnes DE. Effect of the preparewebsite vs an easy-to-read advance directive on advance care planning documentation and engagement among veterans a randomized clinical trial. JAMA Intern Med. 2017;177(8):1102-1109. https://doi.org/10.1001/jamainternmed.2017.1607

Publisher's Note Springer Nature remains neutral with regard to jurisdictional claims in published maps and institutional affiliations. 